\title{
Secondary Trauma of Lay Mental Health Workers in Low-Resource Locations: Bukavu
}

\author{
Janny Jinor, $\mathrm{PhD}$ \\ Walden University, Minneapolis, Minnesota, United States \\ (iD) https://orcid.org/0000-0001-8121-2790
}

Contact: drjinor@gmail.com

\section{Abstract}

A general consensus exists in the literature that working with a trauma population will produce negative personal, psychological, and professional consequences including secondary trauma. However, a significant research gap occurs with regard to how secondary trauma affects psychosocial assistants (PAs) who work in low-resource and conflict-stricken Bukavu in the Democratic Republic of Congo (DRC). The DRC is plagued by psychological problems resulting from numerous past and ongoing conflicts, but sufficient trained mental health personnel and resources are lacking. As a result, the dire responsibility of providing mental health services to survivors of rape has shifted to minimally trained PAs. This phenomenological study explored the lived experiences of secondary trauma through face-toface interviews with 13 PAs in Bukavu. The findings of this study could potentially motivate further research, which will bridge the gap in the understanding of secondary trauma of PAs in the DRC and similar locations. Additionally, this study may be instrumental in restructuring policies and delivery methods favorable to sustainable mental health services in locations such as Bukavu. Finally, it may impact social change through the advancement of mental health services and psychological well-being of the Bukavu community.

Keywords: burnout; compassion fatigue; environment; gender violence; low resources; secondary traumatic stress; self-care; trauma; vicarious trauma

Date Submitted: September 19, 2019 | Date Published: February 25, 2020

\section{Recommended Citation}

Jinor, J. (2020). Secondary trauma of lay mental health workers in low-resource locations: Bukavu. Journal of Social, Behavioral, and Health Sciences, 14, 3-20. https://https://doi.org/10.5590/JSBHS.2020.14.1.02

\section{Introduction}

Cameroon, South Sudan, Somalia, Nicaragua, Myanmar, Haiti, Chad, Mali, Venezuela, Central African Republic, Syria, Libya, Burundi, Cambodia, and the Democratic Republic of Congo (DRC) are examples of locations with developing, ongoing, or postconflict problems. These conflicts result in unstable governments, poverty, insecurity, and a traumatized population that needs a variety of resources including psychological services to regain stability and grow. However, many of these locations are devastated and broken to the 
extent of a complete lack, or a limited number, of resources to ensure access to psychological health resources. Bukavu, DRC, is the location for the focus of this article.

Training and recruiting local lay mental health workers, also known as psychosocial assistants (PAs), is becoming the primary approach to bridging the gap to access mental health treatment, particularly trauma treatment in low-resource areas like the DRC (Daniels \& Ivey, 2007; Fulton et al., 2011; Patel, 2007; Patel et al., 2013; Perry et al., 2014). However, a gap in knowledge exists of how secondary trauma bears on PAs who work with trauma affected populations in a specific location such as Bukavu. Secondary trauma occurs as a result of perceiving the traumatic experiences of patients as described by them. According to Pearlman and Saakvitne (1995), secondary trauma is the consistent, indirect exposure of the worker to different traumatic narrations from trauma survivals. Bride et al. (2004) further described secondary trauma as the symptoms exhibited by a trauma worker in response to continual exposure to patients' traumatic narratives. Note must be taken that secondary trauma and vicarious trauma have been used interchangeably (Figley, 1983, 1995, 2001; Stamm, 1997; Stamm \& Pearce, 1995). Dombo and Gray (2013) and McCann and Pearlman (1990) described vicarious trauma as the gradual personal and internal transformation of a person who works with trauma as a result of continually dispensing empathy to patients. Figley (2001) summarized vicarious trauma as the taking in of the experiences, emotions, and reactions of trauma survivors.

Apart from the term vicarious trauma being used interchangeably with secondary trauma, the following terms are also taken into consideration when discussing the phenomenon of secondary trauma: burnout, compassion fatigue, and stress. Maslach (2003) and Figley (1995), pioneer researchers on the literature of burnout, described it as the feelings and reactions that a person experiences after going through a protracted period of stress at work with no hope of the situation being ameliorated. Other researchers (Hinderer et al., 2014; Lent \& Schwartz, 2012; Maslach, 2003; Schaufeli et al., 2009) stipulated four main components of burnout: (a) lacking the feeling of personal accomplishment, (b) feeling ineffective, (c) being emotionally exhausted, and (d) experiencing depersonalization. Professionals who are chronically burned out exhibit tiredness when performing their work and are unable to fully perform their duties (Maslach et al., 2001; Schaufeli et al., 2009).

Figley (2001) described compassion fatigue as bearing the burden of the suffering of others to an extent that one may begin to feel that he or she is losing one's own sense of individuality relative to the patient. Whereas Ray et al. (2013) described compassion fatigue as physical and psychological complaints reported by mental health workers as a result of bearing the burden of tending to the suffering of others. As suggested by the term, compassion fatigue in this context will mean a point at which a PA simply runs out of compassion as a result of dispensing compassion day after day without any form of replenishment or care for one's own needs. Stress is defined as the feelings that are generated within a person when the person perceives that they are unable to be in control of a situation and fears that they will fail that given situation. Unmanaged stress may lead to burnout (Lent \& Schwartz, 2012).

Following the general agreement in the literature that individuals who work with survivors of trauma may potentially be traumatized by association (Cieslak et al., 2013; Cohen \& Collens, 2013; McCann \& Pearlman, 1990; Williams, 2012), in this qualitative study the lived experiences related to secondary trauma for lay mental health workers was investigated in Eastern DRC due to the uniqueness of such a location. The pursuit of this objective was important because PAs in the DRC work under circumstances that are different than their counterparts in more stable regions of the world. The circumstances that complicate their vulnerability and merit further study are as follows: (a) PAs in the DRC work in proximity to ongoing armed conflict (Verelst et al., 2014). (b) They are exposed to the risk of gender-based violence for which the DRC is notoriously associated (Hatcher, 2013), including the rampant rape of women and girls by armed groups (Autesserre, 2012). A woman can be victimized on the way to the farm, to the market, to church, to visit a friend, or in their homes, and the rape could happen at night or by day (Kristof \& WuDunn, 2009). Initially, 
gender violence was perpetrated mostly by armed and or rebel groups; however, the practice has been normalized by civilian perpetrators to an extent that gender-based violence is described as a way of life in the DRC (Autesserre, 2012). (c) A general lack of trained supervisory personnel exists (Medecins Sans Frontiers, 2011). (d) As a result of the lack of trained personnel, PAs are the frontline workers. (e) PAs' work is carried out in a low-resource location as described by the ranking of the United Nations (2005) Human Development Index. (f) PAs are generally trained for a short period of time, often no more than 2 weeks (Onyut et al., 2004). The training is meant to give them the ability to treat a single mental disorder (Murray \& Jordans, 2016). (g) Based on their minimum training, PAs' skills are basic compared to the tasks and demands of their work with trauma (Dossa, Zunzunegui, Hatem, \& Fraser, 2015; Medecins Sans Frontiers, 2011; Scott et al., 2015). (h) Due to the extent of the post-war issues in the DRC, some PAs may have been exposed to traumatic events that resemble, if not reflect, the events to which their clients are exposed, thus making them particularly susceptible to secondary trauma. (i) Finally, the environment in which these PAs work has very poor infrastructure. For example, poor roads make movement difficult with slow access to patients; telephone networks are unstable and frequently out of range, and electricity is unstable with frequent blackouts.

\section{Background of the Conflict}

The DRC is mainly a postwar country that has suffered decades of wars among different factions of armed groups. A review of the history of the Congo shows no period of real peace. The Congo was colonized by Belgium, known to be one of the most brutal colonial powers, starting with King Leopold II. The end of colonialism in 1960 launched the DRC right into a number of civil strikes and unrest. The country has since survived one form of conflict or power struggle to another. The current state of events in the DRC is characterized by insecurity and persistent eruptions of conflict and human rights abuses (BBC, 2016). The most recent damages to the nation are the result of the conflicts of 1994 and 2003, which resulted in the largest number of war-related deaths across the African continent (Banwell, 2014; Hatcher, 2013). The wars were described by Guy (2014) and Hatcher (2013) as some of the deadliest since World War II, with about 5 million casualties. The conflicts resulted in significant physical and psychological injury to the DRC population including population displacements, lootings, beatings, torture, abductions, and rape and abuse of women and children (Peterman et al., 2011).

Although the wars in the DRC seemingly ended, according to Peterman et al. (2011), a different kind of war has ensued, a sexual violence war exemplified in the rape of women, children, and a silent group of men.

According to Alberti et al. (2010), Casey et al. (2011), Hatcher (2013), and Verelst et al. (2014), sexual violence against women and girls in the DRC became a rampant crime against humanity and still was increasing. Other types of violence like theft, torture, ambush of whole villages, and abductions of women and children were equally rampant (Autesserre, 2012). Verelst et al. (2014) described the war in the DRC as having torn the fabric of the society and continued to fuel violence. The wars, coupled with insecurity and the widespread practice of sexual violence against women and girls, significantly affected community mental health with increased reports of trauma which warranted treatment. However, few, if any, resources could handle these issues (Casey et al., 2011; Medecins Sans Frontiers, 2004).

The phenomenon of secondary trauma in a low-resource location was the specific focus of this study. Secondary trauma was first conceptualized by Figley (1983); he explained that people who work with traumatized patients can begin to exhibit the same symptoms as their patients. Cohen and Collens (2013) elaborated on the personal, psychological, and professional implications of working with trauma patients and stated that workers eventually suffer increased levels of stress, burnout, and secondary trauma if precautions are not taken. Numerous studies (Adams et al., 2006; Cieslak et al., 2013; Cunningham, 2003; Gallavan \& Newman, 2013; McCann \& Pearlman, 1990; Rossi et al., 2012; Sheen et al., 2014; Williams, 2012) supported the idea that an individual who works with traumatized patients is at high risk of experiencing secondary 
trauma. However, no studies had been conducted with the goal to understand how the experiences of secondary trauma bears on the psychological and social wellbeing of PAs in the DRC. Due to the lack of literature regarding the experiences of secondary trauma for this vulnerable population, such knowledge was sought because of the value it could add to the understanding of secondary trauma.

The absence of substantive qualitative data on how secondary trauma affects lay mental health workers in conflict and postconflict locations, and particularly from their own self-reported experiences, necessitated the need to bridge this gap in knowledge. Therefore, the purpose of the present study was to explore the lived experiences of secondary trauma for PAs in the DRC. During the process, I also sought to understand if and how the limited training of PAs had prepared them to be aware of secondary trauma and its implications. Finally, I identified the coping strategies used by PAs as they worked with trauma survivors. Because the focus of this study explored the nature of the lived experience of secondary trauma for PAs, the findings could potentially serve to inform practice on improving the training of PAs and the delivery of their services to trauma survivors. Additionally, the findings could improve sustainability and efficacy of mental health programs in the DRC and similar locations.

To explore this phenomenon, the following research questions were investigated:

Research Question 1: What are the experiences with coping strategies used by PAs in the DRC?

Research Question 2: How has the training of PAs prepared them to be aware of and prevent secondary trauma?

Research Question 3: What are the experiences with coping strategies used by PAs in the DRC?

\section{Method}

The method used to conduct this qualitative phenomenological study was face-to-face in-depth interviews. The goal was to approach 15-20 potential study participants with the aim of interviewing 10-15 in total. I interviewed 13 participants using three broad, open-ended questions, which allowed them to speak extensively about their experiences with secondary trauma.

I contacted participants through three main categories of sites that provided psychosocial assistance to traumatized individuals: nongovernmental organizations (NGOs), hospitals, and other private and community initiatives providing care to trauma survivors. By doing so, the result was a good mix of respondents. With this approach, an opportunity occurred to listen and collect a variety of lived experiences from the respondents related to secondary trauma. Drawing respondents from multiple locations and different establishments minimized the issue of bias that could arise from a single convenient site (Creswell, 2012; King \& Horrocks, 2010; Morrow, 2005; Seidman, 2013).

\section{Participants}

The participants worked for various organizations in the vicinity of, and within the city of Bukavu. Of the 13 participants, 12 were female, and one was male, which appeared to be reflective of the PA population with more female PAs than male PAs in the field. All of the participants were PAs who had been trained for at least 1 week to provide services to trauma survivors. Their experience ranged from 2 to 10 years. They all worked either for NGOs, hospitals, or within the community where they were unaffiliated with any organization. The participants were adults over 18 years of age who all reported that their clientele were survivors of rape, torture, and domestic violence (see Table 1). 
Additional demographic information such as age and education was not included in the table in order to protect the confidentiality and privacy of participants. However, the selection criteria called for adults (a) 18 years and over, (b) trained for a brief period of 1-6 weeks to provide psychosocial services to trauma survivors in the DRC, (c) worked with trauma survivors for a continuation of at least 1 year, (d) no ongoing crisis that impeded the completion of the interview, and (e) the availability to partake in the interview for a duration of $60-90 \mathrm{~min}$.

Table 1. Characteristics of Participants

\begin{tabular}{ccc}
\hline Interviewee & $\begin{array}{c}\text { Years of } \\
\text { experience }\end{array}$ & Area of work \\
\hline 1 & 2 & Community \\
2 & 5 & Hospital \\
3 & 3 & NGO \\
4 & 4 & NGO \\
5 & 10 & Hospital \\
6 & 6 & Hospital \\
7 & 4 & Community \\
8 & 8 & Hospital \\
9 & 7 & Hospital \\
10 & 6 & Community \\
11 & 4 & NGO \\
12 & 5 & Community \\
13 & 3 & Hospital \\
\hline
\end{tabular}

Note. NGO = nongovernmental organization.

In completing this study, the potential risk of triggering emotions for this population was not underestimated. For this reason, a published, free, validated, and reliable instrument called the Primary Care Posttraumatic Stress Disorder Screen for DSM-5 (Prins et al., 2015) was used to assess risk. This instrument is a quick penand-paper screening tool designed to identify individuals with probable posttraumatic stress disorder. If a person answered "yes" to any three out of the five questions on how they were affected by trauma within the past month, the possible participants were screened out of the study for their own protection and to prevent the risk of emotional harm. I used this tool to assess and exclude potential high-risk individuals. High-risk individuals are persons traumatized by their work such that participation in a study might be more harmful than beneficial (Anastas, 2012). I discussed the potential of risk prior to the assessment of possible participants. As a first step, I explained to the participants that if they were disqualified from participating in the study, it was for the sake of protecting them from potential triggers of negative emotions. The screening questionnaire as noted determined the exclusionary criteria. However, no participants were excluded based on a potential for high risk.

\section{Materials}

The interview questions were used for data collection; two voice recording devices were used during data collection. The purpose of using two devices was to guard against possible technical failure in the case of use of one device only. Handwritten notes taken through the data collection process added another source of data. Finally, personal journals written and kept during the study resulted as yet another source of data. 
The interviews began with a demographic section. By following the standard for question formulation in qualitative research, the development of interview questions ensured that solicited responses made sense based on the phenomenon of study (King \& Horrocks, 2010). Further, the questions were written after identifying the gap in the literature that was investigated in the study. Before the data collection process, I initially interviewed one individual as a pilot for the interview questions for the purpose of ensuring clarity. Thus, this initial interview data was excluded from the analysis. Finally, the questions were formulated in an open-ended and clearly understood manner to solicit in-depth discussions by responders.

\section{Analyses}

Data to be analyzed were generated from the responses of the PAs to the interview questions. The coding procedure used for analysis was Bryman's (2015) four stages which involved listening to the recorded responses, understanding the responses as a whole, and then transcribing the data verbatim to written format. Further, by re-reading the transcript and generating main themes and key words, the data were subsequently categorized, themes grouped, associations identified, and redundancy minimized. Finally, the codes were interpreted to make meaning of the data and the significance in relation to the research questions and literature. These procedures are detailed in the body of the proceeding sections.

\section{Results}

In answering the research questions, various themes ensued, as outlined on Table 2. Each theme will be elaborated upon.

\section{Question 1: What Is the Experience of Secondary Trauma for PAs Who Work in the Low-Resource, Trauma-Stricken DRC?}

\section{Personal changes}

All of the participants responded that it was "difficult work." Participants narrated how working with trauma affected them on many levels: individual, family, societal, and work life. Participants' explanations of the effects of working with trauma, exemplifies the theme of personal changes reported by all participants. These changes, they said, affected relations with family and friends as it became harder to love and be kind. Participants reported that working as PAs completely changed their outlook on life and view of society. Participant 7 said, "I do not go out any more; it is too risky, and I make sure I am not out after sunset."

Participant 5 explained that at the end of the day, it was so difficult for her to "be a good person." She tried, but her patience ran out quickly. The idea of a gradual self-transformation as a result of work as PAs resonated through the answers of all the participants. Participants reported difficulties with falling asleep and staying asleep, having nightmares, being edgy and jumpy, including constant preoccupation with things that could go wrong. Physical symptoms, such as headaches, stomach cramps, racing heartbeat, were generally reported by participants. They all explained that over time and without their awareness, they had progressively undergone fundamental shifts in temperament and disposition from how they were before becoming PAs. 
Jinor, 2020

Table 2. Data Themes

\begin{tabular}{|c|c|}
\hline Question & Themes \\
\hline $\begin{array}{l}\text { Question 1: What is the experience of secondary } \\
\text { trauma for PAs who work in the low-resource, } \\
\text { trauma-stricken DRC? }\end{array}$ & $\begin{array}{l}\text { Personal changes } \\
\text { Perseverance } \\
\text { Fear and insecurity } \\
\text { Suffering } \\
\text { "Thinking too much," nervousness, feeling lost } \\
\text { Conflict of compassion } \\
\text { Hopelessness and helplessness } \\
\text { Religion, faith, and the role of God } \\
\text { Conflict }\end{array}$ \\
\hline $\begin{array}{l}\text { Question 2: How has the training of PAs prepared } \\
\text { them to be aware of and prevent secondary } \\
\text { trauma? }\end{array}$ & $\begin{array}{l}\text { Knowledge } \\
\text { Loneliness }\end{array}$ \\
\hline $\begin{array}{l}\text { Question 3: What are the experiences with coping } \\
\text { strategies used by PAs in the DRC? }\end{array}$ & $\begin{array}{l}\text { Strength and faith } \\
\text { Time, money, and coping } \\
\text { Self-protection }\end{array}$ \\
\hline
\end{tabular}

Note. $\mathrm{PA}=$ psychosocial assistant; DRC $=$ Democratic Republic of Congo.

\section{Perseverance}

The theme of perseverance was evident in participants' explanations of the challenges of doing their work, which is only one layer of their daily lives' challenges. Although participants attested that their job was difficult, citing challenges such as insufficient training, heavy caseloads, insecurity related to work, lack of supervision, absence of respect, and low or no salaries, they all expressed the feeling that they are doing a "necessary job." They also articulated the difficulties inherent to their jobs but added that the idea of "giving hope to the women" was comforting. Helping the women believe "there is still some good in the world" by "letting women know that life should not end despite what they have experienced" was reassuring and validated the challenges. The PAs expressed that although things seem hopeless, and they did not believe in the goodness of mankind any more, they still made an effort to encourage the women who sought help from them. They all said that they saw helping as a responsibility with which to persevere.

\section{Fear and insecurity}

Participants spoke about fear as an everyday experience and a constant state of being. They explained that listening to their patients' stories made them fear for their own lives because they could see themselves in the same light as their clients. The participants feared that the same events could happen to them.

Further, four of the participants expressed fear associated with recognition by a perpetrator as a person who provided "listening services" to survivors of violence and rape. On occasion, PAs accompanied their patients to court to testify against the perpetrator. They expressed that most times the perpetrator was set free or released back into the community within a short time. These perpetrators often sought revenge, sometimes with the help of other family members. In the words of Participant 10,

I am constantly afraid or not at ease. I do not stay out late, and I cannot be in the house by myself. I am constantly vigilant. If my eyes meet with someone looking at me, my heart starts to beat fast, especially if it is a man. In that case all I can think of is to escape.

Participant 7 described an incident where a woman in the community was raped. The participant was contacted to help with the crisis as a community member who is a PA. She said that she was lucky at that time 
to have paid airtime on her phone as well as a functioning network signal. She called the police right away, so the police could go to the location of the incident. However, the police told her that they did not have gas in their vehicle to go to that location. As a result, the perpetrator escaped without a trace. She said, "Had the police gone to the location, they may have been able to gather information to follow his trail." The participant explained that she experienced "so much fear after this event" and had "not been able to have a good night's sleep since the event happened." She said that if she did fall asleep, she was woken by nightmares. Participant 7 reported,

Most nights even my heartbeat is too loud. When I am awake in the night, I am listening intensely so that I am not caught off-guard. Sometimes I do seem to hear something or think I did; I get so fearful I start to sweat. My head and heart starts pounding at the same time.

The PAs who worked with NGOs explained that they had to consistently leave the relative safety of their offices in the city in order to make field trips to villages to provide counseling and other services. They talked about their fear of the possibility of being attacked and violated while out in the field or on the way.

Participant 3 reported an incident where their vehicle was stopped by unidentified armed men on the way to a village. They were ordered out of the vehicle and a demand was made for all their valuables. She said, "We had nothing, not even money to pay our way out." While they were held, Participant 3 said,

The stories I have been hearing from the women whom I listen to at work, started playing in my head. I wondered how we will be raped. My last patient was brutally raped. When she came to the hospital, everything was coming out without control. They had put a gun in her, destroyed her completely. All I could think about was this woman; I will be raped like her. I believed we would be raped. I think I half died.

Participant 3 reported that they were verbally tortured and humiliated for about 45 minutes, and for some lucky reason, they were let go:

When we were let go, I do not even know how I walked to the car. I could not shake off the fear. You imagine that. All I could think of was what if there are more of their friends ahead? How are we going to return home?

The fear that was described by the PAs went beyond the fear associated with listening to the accounts of patient trauma stories as elaborated in the literature. While PAs had fear related to hearing their patients' trauma accounts, the possibility of experiencing the same events as their patients was actually highly probable, according to the participants.

\section{Suffering}

Participants unanimously reported "suffering," which they associated with the "torture" resulting from nightmares as well as insomnia. According to participant 2, "I hardly ever have a full night's sleep, so I am often tired and sleepy; however, falling asleep in places other than the bed.” Participant 9 recounted,

I did not have problems with sleeping until one day when something fell on the roof and woke me up. I was so scared that I could not go back to sleep. I had all sorts of thoughts of what it may be. I thought someone was breaking in. I spent the rest of the night afraid and did not sleep any more. The next night I realized I was gripped by fear. I could not sleep. Now I hate the nighttime. These days I do not even expect to sleep.

The theme of suffering was also related to participants' socioeconomic wellbeing. They reported that they were "poor." Their salaries did not stretch past the first week of being paid; as a result, they were unable to meet their family needs. Participant 9 reported, 
I avoid going home after work most days after my salary runs out. Although I am tired, I feel ashamed when I cannot provide for my family as the head of the house. I even become verbally aggressive to my wife because I just don't feel right. I feel rotten inside.

\section{“Thinking too much," nervousness, feeling lost}

Participants reported that they were always "thinking too much." Thinking too much was explained as being generally preoccupied by catastrophic thoughts. They reported often ruminating on "what if." For example, "I am always thinking what if the same thing which happened to my patient happens to me? She is a woman like me."

Participants said that they "are thinking too much" and that it causes suspicion and jumpiness because "every man seems likely to be a potential rapist." Participant 2 said that she is even drowned in her thoughts about her patients' trauma experiences while in church "where I go to seek comfort, but I cannot make my mind rest. Sometimes I think going to church is no longer helpful because the preaching sometimes hints at things that make me want to cry."

\section{Conflict of compassion}

Participants were conflicted about the essence of compassion in a "wicked world" while simultaneously reporting that they felt responsible to be compassionate to their clients despite the personal challenges. Participants in different ways expressed that as a result of listening to so many horrific stories, they felt that their compassion was no longer intact although they desired to show "the best compassion" to their clients. In an equivocal way, the participants said things like, "I do not care for anything since the entire world is so wicked anyway." They questioned the point of being nice in a world where the majority of people are "wicked." On the other hand, they talked about the need to help their clients and to do so no matter what.

Participant 2 said that she found it sometimes difficult to be compassionate with her patients. She listened to the bare minimum of their accounts and "does not encourage the patient to talk more." The thinking behind this reaction was, according to her, that she cannot change how bad the world is, and women continue to be raped anyway. This stance was validated by the growing number of rape victims she had seen in her time as a PA. Participant 2 also recounted, "My caseload continues to increase; I do not remember a period during my work in which I can say that things got better." The increased caseload was a concern for all participants.

\section{Hopelessness and helplessness}

When talking about their experience of secondary trauma, participants generally expressed a resignation about how their work with trauma survivors affected them. The resignation was motivated by the lack of knowledge related to their work. A consistency occurred in the following types of expressions by participants: "The work is difficult, but I have to try to be strong for the women." "Even if I am feeling bad, I have to try to give the women hope that they will feel better." "There is nothing I can do about the way I feel; I just have to leave it in God's hands." "I do not know what to do; only God knows." "Even if I am dying, I have to continue working for the livelihood of my family." "I feel that I must continue to help the women, and one day God will pay me." Although an unrelenting optimism can be inferred from participants' responses, one can also hear the theme of perseverance as they reported that they just had to plod on and continue.

Participants expressed helplessness with not understanding vital components of the practice of service delivery for trauma survivors. This also included helplessness related to not understanding their symptoms, nor knowing how to manage them. They all conveyed a feeling of not knowing what to do to improve their work conditions nor their mental health. They felt resigned to "there is nothing I can do," "what can I do," and plainly stating that the conditions the working conditions "are hopeless," yet the number of trauma survivors continued to increase, an indication according to them that things were not getting better. Participants 
expressed their sense of helplessness as a result of the limits of their knowledge of ways to approach and manage their ever-increasing caseload.

\section{Religion, spirituality, and the role of God}

Participants reported that looking to God for the solution to their problems and suffering was their ultimate hope. At the same time, they expressed doubts based on the horrendous acts of "wickedness," which they saw through their work and in their communities. They also reported that going to church provided only a temporary relief for their problems. Participant 2 reported that sometimes the preaching even provoked her pathos. Others said that they could not fully focus while in church because of racing thoughts, and some said the benefits of going to church lasted only as long as the fellowship, and then they were back to their worries. Participant 10 clearly replied, "I do not even bother to go to church anymore."

\section{Conflict}

The theme of conflict was one source of issues being investigated in this study. According to participants, their communities were characterized by conflict resulting from a politically and economically unstable country. Participants reported that at an individual level and by virtue of living in a conflict-stricken environment like the DRC, people tend to be aggressive. In reporting how working with trauma changed her to be more conflict seeking, one of the participants stated that over time she became quarrelsome. Participant 8 recounted that she became noticeably aggressive to the extent that her children remarked about this tendency. Participant 9 also expressed his regret in the way he responded to his wife when she needed money for grocery shopping. He reported being rude and dismissive to his wife, blaming her for spending irresponsibly. He stated that his anger was rooted in work-related stress and the environmental factors, for example, meager salaries. This setback made it difficult for him to be a proud head of the family which in turn triggered aggression which fed conflict. Echoing the same idea, other participants recounted that working with trauma over time fostered aggressive tendencies in them. These aggressive tendencies emphasized the vicious cycle of conflict for which the DRC is characterized.

\section{Question 2: How Has the Training of PAs Prepared Them to Be Aware of and Prevent Secondary Trauma?}

\section{Knowledge}

The theme of knowledge resonated as participants spoke about their training to be PAs. On a general note, participants were direct and unequivocal about the insufficiency of the training. Respondents also reported that in the rare cases where they were retrained, the knowledge was redundant, lacking new information and details.

Ten out 13 respondents laughed or smirked before answering this question. When the meaning of the laughter was elucidated, respondents said in general that the training was not at all sufficient for the type of work and burden of responsibility. Participant 5 said,

I am nervous every time I have to see a patient because I do not know if I will have the right words to say when the patient relates her story. I try to hide or pretend to be busy when it gets unbearable. Sometimes I beg a colleague to help me with my women because I cannot listen anymore, but she is unable because she has a big workload herself.

Participants reported that they wished they had sufficient training and training refreshers to give them the ability to handle the "load" with their patients. They all expressed desperation about wanting to know what to say to the trauma survivors. Participant 9 said, "I feel like I am betraying the women. They come to talk to me as an expert, and I myself am not confident of the comfort which I can give them. It is very painful for me.” 
It was implied in participants' responses that they lacked sufficient knowledge related to the phenomenon of secondary trauma. However, according to them, the inadequate knowledge about secondary trauma was only attained by their efforts to try to understand their own symptoms. Ten of the participants said that they had associated their symptoms with ailments other than secondary trauma before eventually discovering when talking with others that their symptoms could be work related. Participant 9 said,

I had gone to see the doctor more than once because of headaches and stomach pain and general unease. I was prescribed some paracetamol for the headache and given some stomach pain medication. I remember always thinking that something is wrong with me, but I could not really put a finger on it. I had started to believe that someone had done "voodoo" on me to cause these problems that medication was unable to treat. I thought what else could it be? It was my reaction on the day when something fell on the roof which made me start to really worry. I got uncontrollably shaken and unable to go back to sleep.

Participant 13 said, "When I started having insomnia, I believed that someone had done something to me."

The three participants who said that they had some idea about secondary trauma and the symptoms, although very passively, were the ones with the most years of experience. They were involved in a training which, as they claimed, mentioned such a thing as secondary trauma along with the symptoms. When I asked the participants whether they had received any more information about secondary trauma, the general response was negative.

\section{Loneliness}

Loneliness was a repeated theme that came through the participants' answers. They used the expression loneliness to generally mean the lack of support in dire situations, particularly at work. For example, participants replied that at work a PA is all alone with his or her caseload. The theme of loneliness was summarized by the words of Participant 8 , who said, "You are on your own at work as there is no one to support you because others also are carrying a heavy burden of their own."

\section{Question 3: What Are the Experiences With Coping Strategies Used by PAs in the DRC?}

\section{Strength and faith}

The third question was meant to explore the experiences with coping strategies used by PAs in the DRC. All participants reflected on this question. They generally expressed the need to be strong amidst adversity and to trust in God. This idea came through all the participants' answers. Four of the participants said that the coping strategies they used were either praying, going to church, participating in some social activities, or taking care of the children. The rest of the participants struggled to come up with a coping strategy and had none to report except leaving things to the "mercy of God." In the words of Participant 1, "What can I do? I leave everything in God's hands." However, the participants all said that whatever they did to cope was not enough to take the "thoughts and worries away." Participant 1 commented that she felt a bit comforted when she is in church, but after church services she found that she was "lost in thoughts and worries" related to trauma stories from work. Participant 3 replied, "I stopped going to church because sometimes the messages can be sad and remind me of a lot of sadness," which according to her did not help her state of mind but rather aggravated her feelings of sadness.

Participants explained strength or being strong as one of the only tools they could apply in order to continue to be able to do their work. Responses included, "I have to be strong for the women"; "Even if I feel like crying, I have to not show it. That will not be good for the women, so no matter how strong my feelings are, I must control them in front of the patient"; "I have to just pretend to be strong"; and "The women are looking up to me, and I have to be strong." Thus, strength or the show of strength was largely portrayed as a coping 
mechanism and articulated as, "If I am not strong, what else can I do?" "That is all that I can do, try to be strong."

A general consensus existed that by the time they found out that their work had affected their own wellbeing, the change was already too profound to ignore. Participant 2 related, "At this point there is nothing I can do except to try to be strong." Participant 4 voiced, "There is not much I can do but to continue to help the women and show strength even though it is hard."

\section{Time, money, and coping}

As far as coping strategies, Participant 11 indicated, "I always leave work late. There is no room at all to have fun. Even if I wanted to do something to cope, I do not have the money for it." She laughed and said, "I think you need means to cope with these kinds of problems.” The belief that money is needed for self-care was common among participants. Self-care was viewed as a leisure activity for the socioeconomically privileged or those who have money and time.

Eight of the respondents had worked for more than 3 years, and all of them expressed that it took more than one year of work to realize that they had been impacted by "listening" to their patients' trauma narratives. As for coping, "We leave it in the hands of God." Nine of the participants shared that a person needs to have money and time to practice any form of what they described as "distraction." Of this group, Participant 5 said, "I go to church to try to distract myself from thinking. However, while in church I am even more buried in thought." Participants unanimously articulated that they did not have time for distractions.

Participants reported that they did not understand their symptoms, much less the coping strategies required in PA-client interface. More than half of the participants reported seeking treatment for some kind of fever after failing to understand the somatic problems related to work stress. Participant 13 expressed being pone to stomach cramps and regularly saw the doctor. When medical treatment did not help, she came to the conclusion that she had been poisoned or cursed.

\section{Self-preservation}

Participants indicated that they sometimes "tuned out" during "listening sessions" with patients because they could not process the stories anymore. Participant 7 stated that she deliberately did not ask follow-up questions because that meant more details, and there were times "I simply cannot handle it any more. I feel like I am going crazy." Participant 12 said, "My head starts to ache so much that I cannot listen any more. I feel like crying, but I cannot cry in front of the patient, so I try to block my heart not to take in more."

\section{Discussion}

The findings of this study are consistent with the literature on secondary trauma only to the extent of similarity of symptoms synonymous to secondary trauma as follows: insomnia, nightmares, hopelessness, lack of interest in the job, and depressed feelings, helplessness, anxiety and the preoccupation with their patient's trauma. While the symptoms of secondary trauma reported by participants were consistent with the literature on the phenomenon of secondary trauma, the contribution of the environment in which they worked was most prominent. Participants explained their experiences in a way that reflected the aggravation contributed by the complex work environment. Their explanations of the complexity of their work and location added a different layer to the ways in which they experienced their symptoms of secondary trauma. In spite of the psychological, professional, and personal difficulties involved in doing the job of a PA, they had to grapple with issues of insecurity characterized by their location, including poverty, little access to training and other supportive resources, and political instability. No doubt the environment is relevant when understanding the experiences of secondary trauma for PAs. 
The environmental factor was interpreted based on Orem's $(1959,1964)$ theory, which considered a person's environment to be an influential element to the individual's well-being and his or her ability to take care of self, in order to continue to be productive at work (Masters \& Masters, 2014). For the purpose of clarity, the environmental complexities described by participants included poor and unsafe roads that made movement difficult along with slow access to patients, unstable telephone networks that are frequently out of range, unstable electricity with frequent blackouts, lack of running water, lack of hospitals, and lack of referral resources. Additionally, the DRC is a postwar environment with ongoing crime, security issues, and a high level of gender-related violence (Dolan, 2010; Peterman et al., 2011; Verelst et al., 2014). Although I did not ask the question on participants' understanding of secondary trauma, their lack of sufficient knowledge about the phenomenon was implied by their answers related to the question on coping. Their lack of understanding of symptoms of secondary trauma and coping skills to manage the symptoms indicated a void in practice. In desperation, PAs sought the hand of God for coping. Moreover, if they could not understand nor explain their symptoms, then the answer might come from a superior being like God. However, they reported that their symptoms were beyond superficial, and they did not find solace in church. In not being able to find comfort in church and with no other resources, participants expressed an attitude of despair toward their difficulties. They rationalized that they had no other choice but to try to be strong and wait for God's mercy.

The void and the lack of knowledge relating to secondary trauma depleted the PAs' confidence in doing their work and thus their efficacy. In the context of Albert Bandura's (1986) social cognitive theory of self-efficacy, if PAs are sufficiently trained to understand their job, including an understanding of its implications, they will be more confident. In this way, they will be more efficacious instead of resigned. Participants reported that they were usually in doubt about effective ways to deal with critical clients. According to a number of participants, they hide or pretend to be busy rather than be next in line for the assignment of a potential "difficult case." They explained that the reason for this avoidance is because they are unsure of the appropriate approach in these situations. This expression of a lack of confidence in ways to approach clients in crisis is clear evidence of the lack of adequate preparation in the form of training for their job roles. Bandura's theory was used to understand how the shortcomings in PA training and knowledge of secondary trauma can impact the PAs' efficacy.

The lack of supportive tools, including supervision, contributed to making the work of PAs difficult. These voids, at minimum, accelerated the exposure to secondary trauma of PAs. The lack of supervision made the responsibility of the PA daunting when consideration is given to the difficulty of their work. So, in spite of PAs' assertion that their role was important and that they needed to persevere in order to be available to their clients, their own well-being is at risk. The lack of supervision meant that when a PA was in a crisis situation, be it with self or clients, they were practically on their own.

The reported lack of respect and low remuneration of PAs showed that the importance of their role in contributing to mental health treatment in the DRC might be undermined. The consequence was exemplified by PAs' accounts of their strength running out, synonymous to burnout, according to the literature that was cited on secondary trauma. Dwindling strength among the PAs can be deduced from the accounts of PAs' avoidance of clients, especially in crisis situations. This avoidance can also be interpreted to indicate a disinterest in the job comparable to compassion fatigue, according to Figley (2001), or it could be an attempt at self-preservation in the absence of constructive coping skills. Participants reported that listening to many client accounts over time led to difficulty continuing to attend to more clients. This idea fits with the explanations of Hinderer et al. (2014), Lent and Schwartz (2012), Maslach (2003), and Schaufeli et al. (2009), who expressed that when a worker is burned out, they feel ineffective, emotionally exhausted, and more likely to depersonalize their patients.

Inferring from the participants' responses, the participants experienced severe limitations in their ability to provide services fulfilling to their patients and consequently to themselves. In addition to the psychological 
symptoms previously described, participants expressed experiencing physical symptoms synonymous to burnout as described by Maslach (2003) and Figley (1995). Participants reported that many times they left work at the end of the day with headaches and were completely overwhelmed and lost.

The initial general belief that the symptoms were possibly related to voodoo indicated that PAs had insufficient knowledge about secondary trauma. Additionally, PAs said that the only way they came to understand that their symptoms were psychological was after multiple doctor and traditional healer visits with the physical symptoms. After understanding that their symptoms were psychological, they were completely lost for next steps.

The literature showed a dire need for the service of PAs in low-resource areas, including the DRC, to deal with the ever mounting, mental health issues resulting from strife (Neuner et al., 2008; Onyut et al., 2004; Perry et al., 2014). Evidence also showed that in the absence of skilled professionals in the field of mental health, the job of workers like PAs yields fruitful results (Bolton et al., 2003; Hall et al., 2014; Verdeli et al., 2003); however, there is a gap between the understanding of the roles of these workers and the assurance that their services continue to be sustainable. For these services to be sustainable, resources must be directed primarily toward understanding the burden of PAs and aligning their services with ongoing education related to their work and comprehensive resilience building activities.

\section{Limitations}

The main limitation of this study was the small sample size. A small sample size limits the ability to generalize study results (Lincoln \& Guba, 1985). In spite of this limitation, transferability to a different time, place, situation, and group of people (Lincoln \& Guba, 1985) is possible. The use of qualitative interviewing as a format for data collection explored the issues of secondary trauma in great detail, thus making transferability possible. Studies of this nature explore the lived experiences of individuals in order to understand the essence of a given phenomenon. To that effect, it is the gathering of detailed and complex data from a small sample that could trigger further research on a given phenomenon.

In conclusion, while the focus of this study was on Eastern DRC, a significant number of potential and ongoing conflicts in the world exist. These events often result in unstable environments with traumatized populations, as in the case of the DRC. The issues of minimal resources and absence of skills plague such locations. In order to obtain relief in a future with insufficient skilled mental health personnel, task shifting to lay workers may continue to be the way forward. Indeed, as discussed by the World Health Organization (2010), this may be the most effective way of tackling global health issues and the shortage of skilled professionals in rural areas. As this seems to be the case, this study provides the much-needed wakeup call to start directing resources in a way that understands and protects these workers. Considering the results of this study, PAs are not equipped with the minimum tools needed to provide mental health services in a sustainable manner. The risk of psychological harm for them is high, and this translates to escalating and worsening the issue of trauma for the DRC. Without sufficient training and retraining of the PAs, and by not teaching them about the implications of working with trauma and the prevention of secondary trauma and other psychological problems related to their line of work, organizations involved in mental health prevention and treatment in low-resource locations risk losing a valuable asset, the PAs, while exacerbating the problem of secondary trauma. 


\section{References}

Adams, R. E., Boscarino, J. A., \& Figley, C. R. (2006). Compassion fatigue and psychological distress among social workers: A validation study. The American Journal of Orthopsychiatry, 76(1), 103-108. https://doi.org/10.1037/0002-9432.76.1.103

Alberti, K. P., Grellety, E., Lin, Y. C., Polonsky, J., Coppens, K., Encinas, L., \& Mondonge, V. (2010). Violence against civilians and access to health care in North Kivu, Democratic Republic of Congo: Three crosssectional surveys. Conflict and Health, 4, 17. https://doi.org/10.1186/1752-1505-4-17

Anastas, J. W. (2012). Research design for social work and the human services. Columbia University Press.

Autesserre, S. (2012). Dangerous tales: Dominant narratives on the Congo and their unintended consequences. African Affairs, 111(443), 202-222. https://doi.org/10.1093/afraf/adro80

Bandura, A. (1986). Social foundations of thought and action: A social cognitive theory. Prentice Hall.

Banwell, S. (2014). Rape and sexual violence in the Democratic Republic of Congo: A case study of genderbased violence. Journal of Gender Studies, 23(1), 45-58. https://doi.org/10.1080/09589236.2012.726603

BBC. (2016). DR Congo country profile. http://www.bbc.com/news/world-africa-13283212

Bolton, P., Bass, J., Neugebauer, R., Verdeli, H., Clougherty, K. F., Wickramaratne, P., \& Weissman, M. (2003). Group interpersonal psychotherapy for depression in rural Uganda: A randomized controlled trial. JAMA, 289(23), 3117-3124. https://doi.org/10.1001/jama.289.23.3117

Bride, B. E., Robinson, M. M., Yegidis, B., \& Figley, C. R. (2004). Development and validation of the secondary traumatic stress scale. Research on Social Work Practice, 14(1), 27-35.

Bryman, A. (2015). Social research methods. Oxford University Press.

Casey, S. E., Gallagher, M. C., Makanda, B. R., Meyers, J. L., Vinas, M. C., \& Austin, J. (2011). Care-seeking behavior by survivors of sexual assault in the Democratic Republic of the Congo. American Journal of Public Health, 101(6), 1054-1055. https://doi.org/10.2105/AJPH.2010.300045

Cieslak, R., Shoji, K., Luszczynska, A., Taylor, S., Rogala, A., \& Benight, C. C. (2013). Secondary trauma selfefficacy: Concept and its measurement. Psychological Assessment, 25(3), 917-928. https://doi.org/10.1037/a0032687

Cohen, K., \& Collens, P. (2013). The impact of trauma work on trauma workers: A metasynthesis on vicarious trauma and vicarious posttraumatic growth. Psychological Trauma: Theory, Research, Practice, and Policy, 5(6), 570-580. https://doi.org/10.1037/a0030388

Creswell, J. W. (2012). Qualitative inquiry and research design: Choosing among five approaches. Sage.

Cunningham, M. (2003). Impact of trauma work on social work clinicians: Empirical findings. Social Work, 48(4), 451-459. https://doi.org/10.1093/sw/48.4.451

Daniels, T., \& Ivey, A. (2007). Microcounseling: Making skills training work in a multicultural world. Charles C. Thomas.

Dolan, C. (2010). War is not yet over. Community perceptions of sexual violence and its underpinnings in Eastern DRC. Routledge.

Dombo, E. A., \& Gray, C. (2013). Engaging spirituality in addressing vicarious trauma in clinical social workers: A self-care model. Social Work and Christianity, 4O(1), 89-104. 
Dossa, N. I., Zunzunegui, M. V., Hatem, M., \& Fraser, W. D. (2015). Mental health disorders among victims of conflict-related sexual violence in the Democratic Republic of Congo. Journal of Interpersonal Violence, 3o(13), 2199-2220.

Figley, C. R. (1983). Catastrophes: An overview of family reactions. In C. R. Figley \& H. I. McCubbin (Eds.), Stress and the family II: Coping with catastrophe (pp. 3-20). Brunner/Mazel.

Figley, C. R. (1995). Compassion fatigue as secondary traumatic stress disorder. Brunner/Mazel.

Figley, C. R. (2001). Compassion fatigue: Psychotherapists' chronic lack of self-care. Journal of Clinical Psychology, 58(11), 1433-1441.

Fulton, B. D., Scheffler, R. M., Sparkes, S. P., Auh, E. Y., Vujicic, M., \& Soucat, A. (2011). Health workforce skill mix and task shifting in low-income countries: A review of recent evidence. Human Resources for Health, 9, 1. https://doi.org/10.1186/1478-4491-9-1

Gallavan, D. B., \& Newman, J. L. (2013). Predictors of burnout among correctional mental health professionals. Psychological Services, 1O(1), 115-122. https://doi.org/10.1037/a0031341

Guy, K. M. (2014). Mai-Mai militia and sexual violence in Democratic Republic of the Congo. International Journal of Emergency Mental Health, 16(2), 366-372.

Hall, B. J., Bolton, P. A., Annan, J., Kaysen, D., Robinette, K., Cetinoglu, T., \& Bass, J. K. (2014). The effect of cognitive therapy on structural social capital: Results from a randomized controlled trial among sexual violence survivors in the Democratic Republic of the Congo. American Journal of Public Health, 104(9), 1680-1686. https://doi.org/10.2105/AJPH.2014.301981

Hatcher, J. (2013, November 5). Eastern Congo grapples with mental health catastrophe after years of war. https://www.theguardian.com/world/2013/nov/05/eastern-congo-mental-health-catastrophebrutality

Hinderer, K. A., Von Rueden, K. T., Friedmann, E., McQuilllan, K. A., Gilmore, R., Kramer, B., \& Murray, M. (2014). Burnout, compassion fatigue, compassion satisfaction, and secondary traumatic stress in trauma nurses. Journal of Trauma Nursing, 21(4), 160-169.

King, N., \& Horrocks, C. (2010). Interviews in qualitative research. Sage.

Kristof, N. D., \& WuDunn, S. (2009). Half the sky: Turning oppression into opportunity for women worldwide. Alfred A. Knopf.

Lent, J., \& Schwartz, R. (2012). The impact of work setting, demographic characteristics, and personality factors related to burnout among professional counselors. Journal of Mental Health Counseling, 34(4), 355-372.

Lincoln, Y. S., \& Guba, E. G. (1985). Naturalistic inquiry. Sage.

Maslach, C. (2003). Job burnout: New directions in research and intervention. Current Directions in Psychological Science, 12(5), 189-192.

Maslach, C., Schaufeli, W. B., \& Leiter, M. P. (2001). Job burnout. Annual Review of Psychology, 52(1), 397423.

Masters, K., \& Masters, U. (2014). Nursing theories: Framework for professional practice. Jones \& Bartlett.

McCann, I. L., \& Pearlman, L. A. (1990). Vicarious traumatization: A framework for understanding the psychological effects of working with victims. Journal of Traumatic Stress, 3(1), 131-149. https://doi.org/10.1007/BFo0975140 
Medecins Sans Frontiers. (2004). I have no joy, no peace of mind: Medical, psychosocial and socio-economic consequences of sexual violence in Eastern DRC. http://www.doctorswithoutborders.org/publications/reports/2004/sexualviolence_2004.pdf

Medecins Sans Frontiers. (2011). Annual plan DRC.

Morrow, S. L. (2005). Quality and trustworthiness in qualitative research in counseling psychology. Journal of Counseling Psychology, 52(2), 250-260. https://doi.org/10.1037/0022-0167.52.2.250

Murray, L. K., \& Jordans, M. J. D. (2016). Rethinking the service delivery system of psychological interventions in low- and middle-income countries. BMC Psychiatry, 16, 1-6. https://doi.org/10.1186/s12888-016-0938-y

Neuner, F., Onyut, P. L., Ertl, V., Odenwald, M., Schauer, E., \& Elbert, T. (2008). Treatment of posttraumatic stress disorder by trained lay counselors in an African refugee settlement: A randomized controlled trial. Journal of Consulting and Clinical Psychology, 76(4), 686.

Onyut, L. P., Neuner, F., Schauer, E., Ertl, V., Odenwald, M., Schauer, M., \& Elbert, T. (2004). The Nakivale camp mental health project: Building local competency for psychological assistance to traumatized refugees. Intervention, 2(2), 90-107.

Orem, D. (1959). Guides for developing curriculum for the education of practical nurses. U.S. Government Printing Office.

Orem, D. (1964). Nursing content in preservice nursing curriculums: The proceedings. Catholic University of America Press.

Patel, V. (2007). Mental health in low- and middle-income countries. British Medical Bulletin, 81-82(1), 8196. https://doi.org/10.1093/bmb/ldmo10

Patel, V., Minas, H., Cohen, A., \& Prince, M. (2013). Global mental health: Principles and practice. Oxford University Press.

Pearlman, L., \& Saakvitne, K. W. (1995). Trauma and the therapist: Countertransference and vicarious traumatization in psychotherapy with incest survivors. Norton.

Perry, H. B., Zulliger, R., \& Rogers, M. M. (2014). Community health workers in low-, middle-, and highincome countries: An overview of their history, recent evolution, and current effectiveness. Annual Review of Public Health, 35, 399-421. https://doi.org/10.1146/annurevpublhealth-032013-182354

Peterman, A., Palermo, T., \& Bredenkamp, C. (2011). Estimates and determinants of sexual violence against women in the Democratic Republic of Congo. American Journal of Public Health, 101(6), 1060-1067. https://doi.org/10.2105/AJPH.2010.300070

Prins, A., Bovin, M. J., Kimerling, R., Kaloupek, D. G., Marx, B. P., Pless Kaiser, A., \& Schnurr, P. P. (2015). The Primary Care PTSD Screen for DSM-5 (PC-PTSD-5). [Measurement instrument]. https://www.ptsd.va.gov/professional/assessment/screens/pc-ptsd.asp

Ray, S. L., Wong, C., White, D., \& Heaslip, K. (2013). Compassion satisfaction, compassion fatigue, work life conditions, and burnout among frontline mental healthcare professionals. Traumatology, 19(4), 255267. https://doi.org/10.1177/1534765612471144

Rossi, A., Cetrano, G., Pertile, R., Rabbi, L., Donisi, V., Grigoletti, L., \& Amaddeo, F. (2012). Burnout, compassion fatigue, and compassion satisfaction among staff in community based mental health services. Psychiatry Research, 200(2-3), 933-938. https://doi.org/10.1016/j.psychres.2012.07.029

Schaufeli, W. B., Leiter, M. P., \& Maslach, C. (2009). Burnout: Thirty-five years of research and practice. Career Development International, 14, 204-220. 
Scott, J., Rouhani, S., Greiner, A., Albutt, K., Kuwert, P., Hacker, M. R., \& Bartels, S. (2015). Respondent driven sampling to assess mental health outcomes, stigma, and acceptance among women raising children born from sexual violence-related pregnancies in Eastern Democratic Republic of Congo. British Medical Journal, 5(4), e007057.

Seidman, I. (2013). Interviewing as qualitative research: A guide for researchers in education and the social sciences. Sage.

Sheen, K., Slade, P., \& Spicy, H. (2014). An integrative review of the impact of indirect trauma exposure in health professionals and potential issues of salience for midwives. Journal of Advanced Nursing, 7O(4), 729-743. https://doi.org/10.1111/jan.12274

Stamm, B. H. (1997). Work-related secondary trauma stress. PTSD Research Quarterly, 8, 25-34.

Stamm, B. H., \& Pearce, F. W. (1995). Creating virtual community: Telemedicine applications for self-care. In B. H. Stamm (Ed.), Secondary traumatic stress: Self-care issues for clinicians, researchers, and educators (pp. 179-207). Sidran Press.

United Nations. (2005). United Nations human development index. http://hdr.undp.org/sites/default/files/reports/266/hdro5 complete.pdf

Verdeli, H., Clougherty, K., Bolton, P., Speelman, L., Lincoln, N., Bass, J., \& Weissman, M. M. (2003). Adapting group interpersonal psychotherapy for a developing country: Experience in rural Uganda. World Psychiatry, 2(2), 114-120.

Verelst, A., De Schryver, M., Broekaert, E., \& Derluyn, I. (2014). Mental health of victims of sexual violence in Eastern Congo: Associations with daily stressors, stigma, and labeling. BMC Women's Health, 14, 106. https://doi.org/10.1186/1472-6874-14-106

Williams, A. (2012). Emotion work in paramedic practice: The implications for nurse educators. Nurse Education Today, 32(4), 368-372. https://doi.org/10.1016/j.nedt.2011.05.008

World Health Organization. (2010). Intervention guide for mental, neurological, and substance use disorders in non-specialized health settings.

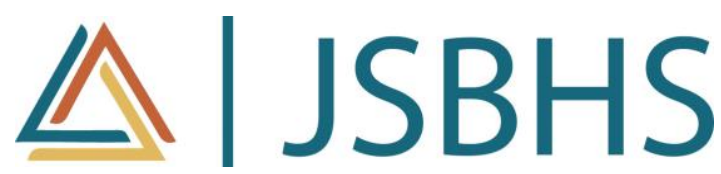

The Journal of Social, Behavioral, and Health Sciences (JSBHS), co-sponsored by the College of Health Sciences and the College of Social and Behavioral Sciences at Walden University, is a peer-reviewed, online, interdisciplinary journal focusing on theoretically-based research that addresses contemporary national and international issues. JSBHS articles include peer-reviewed research reports, brief resports, comprehensive literature reviews, books reviews, and student research. 